\title{
Stability constant of rare earth metals with substituted Thiazoles at 298.15K
}

\author{
A. B. Naik* and M. S. Poharkar \\ Physical Chemistry Laboratory, Department of Chemical Technology, Sant Gadge Baba Amaravati \\ University Amravati-444602 (INDIA) \\ anilnaik@sgbau.ac.in
}

Keywords: Thiazole, rare earth metal ions, Stability constant, $\mathrm{pH}$ metric, Dx-water, spectrophotometric.

\begin{abstract}
The stability constant on complexation of rare earth metal ions Eu(III), Gd (III), $\mathrm{Nd}(\mathrm{III})$ and $\mathrm{Tb}$ (III) with substituted thiazole in $70 \%$ Dioxane (Dx)-water mixture have been determined by a $\mathrm{pH}$ and spectrophotometric method at $298.15 \mathrm{~K}$ and ionic strength $0.1 \mathrm{~mol} . \mathrm{dm}^{-3}$ (sodium perchlorate).

At constant temperature, the stability constant of the formed complexes decreases in the order $\mathrm{Tb}$ (III), Gd(III), Eu (III), Nd (III). The dissociation process is non-spontaneous, endothermic and entrophically unfavorable while formation of metal complexes has been found to be spontaneous, endothermic and entrophically favorable.
\end{abstract}

\section{Introduction}

Heterocyclic compounds have been major interest of research due to oxygen, nitrogen and sulphar $^{[1]}$. Thiazoles have become the focus of interest in the recent past on account of their medicinal, biological and agrochemical activities ${ }^{[2-4]}$. There are large number of synthetic compounds with thiazole nucleus having application as anticancer ${ }^{[5]}$, analgesic ${ }^{[6]}$, antitubercular ${ }^{[7]}$, antidiabatic $^{[8]}$ etc. Many of the hetercyclic compounds that can affect the biological and ecological behavior of the lanthanide ions ${ }^{[9]}$. Studies on complex formation by tripositive rare earth ions with biologically active ligands are in progress because of their role in biochemical processes. The metal complexes with some heterocyclic compounds in aqueous solution has been determined by various authors $^{[10-12]}$.

The present work is the continuation of our earlier of metal complexation ${ }^{[13-14]}$. The complexation of substituted thiazoles with rare earth metal ions in the $1: 1$ ratio at $298.15 \mathrm{~K}$. The ionic strength is maintained by addition of sodium perchlorate solution. Since the ligand is insoluble in water, hence $70 \%$ dioxane-water (Dx-water) mixture used as solvent.

\section{Materials and method:}

The rare earth metal ions (Sigma Aldrich), sodium perchlorate, hydroxy thiazole (Hi-media), perchloric acid (Qualigen), sodium hydroxide (Thomes Baker) (DMF) of AnalR grade used without purification. The ligand solutions were prepared by dissolving an accurate amount in an organicaqueous mixture in standard flask with airtight caps and the mass measurement were performed using high precision digital balance (Shimadzu, Japan accuracy $\pm 0.1 \mathrm{mg}$ ). Dilute perchloric acid solution, standard sodium hydroxide and nitrates of rare earth metal ions $\left(1.0 \times 10^{-2} \mathrm{~mol}^{-\mathrm{dm}^{-3}}\right)$ standardised by literature method ${ }^{[15-17]}$.

A $\mathrm{pH}$ meter (827, Metrohm, Switzerland) was used for $\mathrm{pH}$ measurements. The $\mathrm{pH}$ meter has a sensitivity of 0.01 units and all measurements were carried out at $298.15 \mathrm{~K}$. The ionic strength was maintained by addition of sodium perchlorate. The instrument was calibrated before each titration with an aqueous standard buffer solution of $\mathrm{pH} 4.20,7.00$ and 9.10. The solution were prepared (total volume $\left.25 \mathrm{~cm}^{3}\right)$; a) perchloric acid $\left(2.0 \times 10^{-2} \mathrm{~mol} \mathrm{dm}{ }^{-3}, 2.5 \mathrm{ml}\right)+$ sodium perchlorate $(2.0 \mathrm{x}$ $\left.\left.10^{-2} \mathrm{~mol} \mathrm{dm}^{-3}, 2.5 \mathrm{ml}\right), \mathrm{b}\right)$ solution a + ligand $\left(1.0 \times 10^{-2} \mathrm{~mol} \mathrm{dm}^{-3}, 5 \mathrm{ml}\right)$ and c) solution $\mathrm{b}+$ metal 
ion $\left(1.0 \times 10^{-2} \mathrm{~mol} \mathrm{dm}^{-3}, 1 \mathrm{ml}\right)$. The ligand was acidfied with perchloric acid in a $70 \% \mathrm{Dx}$-water medium. The ligand was titrated against standard sodium hydroxide using Calvin-Wilson-Bjerrum $\mathrm{pH}$ titration techniques ${ }^{[18,19]}$.

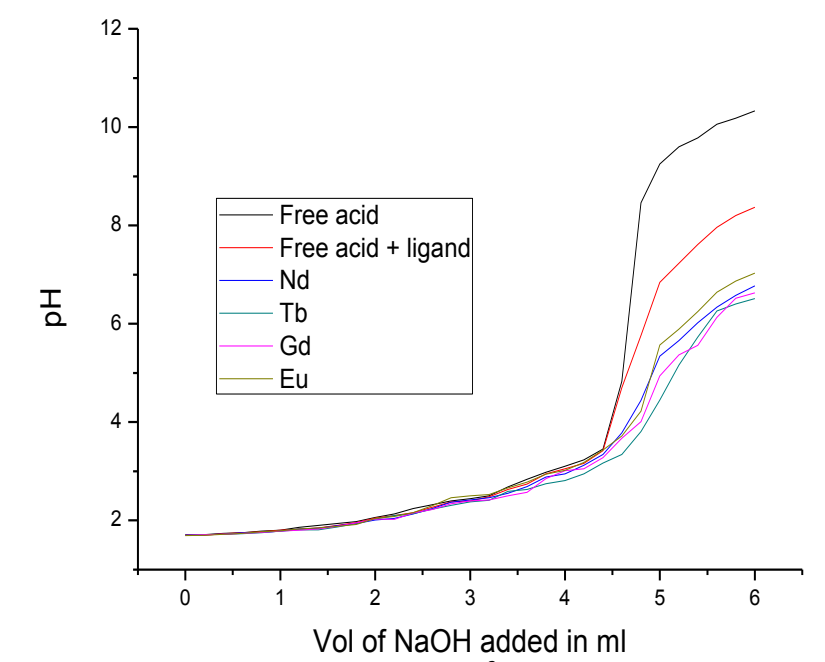

Fig. $1 \mathrm{pH}$ vs vol of $\mathrm{NaOH}, \mu=0.1 \mathrm{~mol}^{-\mathrm{dm}^{-3}}$ at $298.15 \mathrm{~K}$
The spectrophotometric measurements were performed by Job's method ${ }^{[20]}$ on a UV-VIS spectrophotometer (Model 1800, Shimadzu, Japan) accuracy \pm 0.005 with spectral range 180 $1100 \mathrm{~nm}$. The equimolar solution of ligand and rare earth metal ions; $\mathrm{Eu}(\mathrm{III})$, Gd (III) and $\mathrm{Tb}(\mathrm{III})$ were mixed in different proportions with the $\mathrm{pH}$ range 2-3 and $\mu=0.1$ maintained by addition of sodium hydroxide and sodium perchlorate respectively. The concentration of the complex is at a maximum when reagents are in the ratio of their stoichiometric proportions in the complex.

\section{Results and Discussion}

Figure 1 shows the nature of the acid curve and ligand curve. In the initial stages of titration the $\mathrm{pH}$ values of the ligand curve slightly higher than the corresponding values of acid curve at the same volume of alkali added. This is due to formation of cation of thaizole resulting in the decrease in $\mathrm{H}^{+}$ ion concentration of the reation mixture. In the present study, the proton ligand stability constants for thiazole and the metal-ligand stability constants for the complexes of $\mathrm{Eu}(\mathrm{III}), \mathrm{Gd}(\mathrm{III}), \mathrm{Nd}(\mathrm{III})$ and $\mathrm{Tb}(\mathrm{III})$ with thiazole were determined by carrying out he acid, ligand and metal titrations at $298.15 \mathrm{~K}$ by maintaining the ionic strength. Fig 1 . Exhibits a set of acid, ligand and four metal titration curves at $\mu=0.1 \mathrm{~mol} . \mathrm{dm}^{-3}$ and $\mathrm{T}=298.15 \mathrm{~K}$. At higher volumes of alkali added, the relatively large drop in $\mathrm{pH}$ in metal titrations with respect to the ligand titration curve and the formation of metal complex ${ }^{[21]}$.

The extent of deviation is due to dissociation of hydroxyl group completely. The proton-ligand dissociation constant and metal stability constants of $\mathrm{HL}$ with $\mathrm{Eu}(\mathrm{III}), \mathrm{Gd}$ (III), $\mathrm{Nd}$ (III) and Tb (III) have been determined $\mathrm{pH}$ and spectrophotometrically. The $\mathrm{pH}$ metric study were carried out in $0.1 \mathrm{M} \mathrm{NaClO}_{4}$ at constant temperature. The proton ligand formation was calculated by Irving Rossotti method ${ }^{[22,23]}$.

The accurate $\mathrm{pK}$ values of complexes were calculated by half integral method and concordance with pointwise calculation method. The pK values of ligand by half integral method and pointwise calculation method are found to be 8.40 and $8.51 \pm 0.03$ respectively. There is good agreement obtained by the methods. The proton ligand formation number $\bar{n}_{A}$ were calculated from the following equation;

$$
\bar{n}_{A}=\gamma-\frac{\left(E^{0}+N\right)\left(V_{2}-V_{1}\right)}{\left(V^{0}+V_{1}\right) T_{L}^{0}}
$$

Where $\gamma$ denotes the number of dissociable protons, $\mathrm{N}$ is the concentration of sodium hydroxide, $\mathrm{V}_{2}$ and $\mathrm{V}_{1}$ are the volume of alkali added to reach the same $\mathrm{pH}$ reading, $\left(\mathrm{V}_{2}-\mathrm{V}_{1}\right)$ is the displacement values of ligand curve relative to acid curve, $\mathrm{V}^{0}$ is the intial volume of the reaction mixture, $\mathrm{E}^{0}$ and $\mathrm{T}_{\mathrm{L}}{ }^{0}$ are the resultant concentration of sodium perchlorate and concentration of ligand respectively. In the present study $\mathrm{pH}$ titration curve shows only one inflection point indicated that there is only one acid acidic group. 
The metal-ligand stability constants determined by following equation;

$$
\bar{n}=\frac{\left(V_{3}-V_{2}\right)\left(E^{0}+N\right)}{\left(V^{0}+V_{2}\right) T_{m}^{0}}
$$

Where $\mathrm{N}, \mathrm{E}^{0}, \mathrm{~V}^{0}$ and $\mathrm{V}_{2}$ have the same significance as in above eq, $\mathrm{V}_{3}$ is the volume of alkali added in the metal titration to attain the $\mathrm{pH}$ reading and $\mathrm{T}_{\mathrm{L}}{ }^{0}$ is the concentration of the metal ion in the reaction mixture. The stability constants calculated for the systems have been calculated and tabulated in Table 1. Metal-ligand stability constants of the complexes from the table showed that there is no appreciable difference between $\log \mathrm{K}_{1}$ and $\log \mathrm{K}_{2}$ values, that indicates the formation of complexes simultaneously.

Table 1 Metal stability constants of thiazole complexes at constant ionic strength in $70 \%$ Dx-water at $298.15 \mathrm{~K}$

\begin{tabular}{|l|l|l|l|}
\hline System & \multicolumn{2}{|c|}{$\mathrm{pH}$ metric $(\log \mathrm{K})$} & Spectrophotometric $(\log \mathrm{K})$ \\
\hline & Half Integral & Pointwise calculation & \\
\hline Nd (III)-L & $\log \mathrm{K}_{1}=7.40$ & $\log \mathrm{K}_{1}=7.68$ & $\log \mathrm{K}_{1}=7.57$ \\
& $\log \mathrm{K}_{2}=5.29$ & $\log \mathrm{K}_{2}=5.22$ & $\log \mathrm{K}_{2}=5.44$ \\
\hline Eu (III)-L & $\log \mathrm{K}_{1}=7.60$ & $\log \mathrm{K}_{1}=6.35$ & $\log \mathrm{K}_{1}=6.70$ \\
& $\log \mathrm{K}_{2}=5.37$ & $\log \mathrm{K}_{2}=5.39$ & $\log \mathrm{K}_{2}=5.49$ \\
\hline Gd (III)-L & $\log \mathrm{K}_{1}=7.78$ & $\log \mathrm{K}_{1}=7.26$ & $\log \mathrm{K}_{1}=7.83$ \\
& $\log \mathrm{K}_{2}=5.49$ & $\log \mathrm{K}_{2}=5.41$ & $\log \mathrm{K}_{2}=5.54$ \\
\hline Tb (III)-L & $\log \mathrm{K}_{1}=7.95$ & $\log \mathrm{K}_{1}=7.53$ & $\log \mathrm{K}_{1}=7.97$ \\
& $\log \mathrm{K}_{2}=5.57$ & $\log \mathrm{K}_{2}=5.49$ & $\log \mathrm{K}_{2}=5.69$ \\
\hline
\end{tabular}

Spectrophotometric studies: Using the continous variations method, the determination of absorbance of solution of metal ion with thiazole of concentration. The conditional metal-ligand stability constants calculated using following expression;

$$
K=\frac{x}{(a-x)(b-x)}
$$

Where $\mathrm{K}=$ Conditional metal-ligand stability constant, $x=$ concentration of complex, $\mathrm{a}$ and $\mathrm{b}=$ concentration of metal ion and ligand.

The conditional stability constants are found to be slightly greater than the real stability. It may be due to the concentration of free acid at particular $\mathrm{pH}$ was not taken into account and variation in temperature. The agreement between the values obtained from the both techniques is fairly good.

\section{Conclusion}

The metal-ligand formation value of $\tilde{\mathrm{n}}$ was $\approx 2$, indicating formation of 1:1 and 1:2 complex only. The metal ion solution used in the present work was very dilute therefore there is mere possibility of the formation of polynuclear complexes. At constant temperature the stability of the ligand increases in the order $\mathrm{Nd}(\mathrm{III})>\mathrm{Eu}(\mathrm{III})>\mathrm{Gd}$ (III) $>\mathrm{Tb}$ (III). This order largly reflects that the stability of $\mathrm{Nd}$ (III) complexes is larger than those of other metals. The conditional stability constants are found to be slightly greater than the real stability.

\section{Acknowledgement}

The authors are thankful to Department of Science and Technology (SERB-DST, New Delhi) for their financial support (SERB/F/4566/2013-14). 


\section{References}

[1] P. B. Morey and A. B. Naik, Int. Lett. Chem. Phys. Astronomy. 59 (2015) 186-98.

[2] P. B. Morey and A. B. Naik, Int. J Sci. Res. (2015) 211-214.

[3] J. N. Greul, O. Gaertzen, R. Dunkel, S. Hillebrand, K. Ilg, P. Schreiev, V. Hadano, S. Bennabi, US Patent 00300024 A1 (2009).

[4] A. B. Naik, Int. Lett. Chem. Phys. Astronomy. 61 (2015) 105-109.

[5] S. Kok, R. Gambari, C. Chui, M. Yuen, E. Lin, R. Wong, Bio. Med. Chem. 16 (2008) 36263631 .

[6] M. N. Bhoi, M. A. Borad, H. D. Patel, Synth. Com. 44 (2014) 2427-2457.

[7] S. R. Pattan, A. A. Bukitagar, J. S. Pattan, B. P. Kapadnis, S. G. Jadhav, Ind. J. Chem. 48B (2009) 1033-1037.

[8] S. R. Pattan, C. Suresh, V. D. Pujar, V. V. K. Reddy, V. P. Rasal, B. C. Koti, Ind. J. Chem. 44B (2005) 2404-2408.

[9] A. B. Naik and M. L. Narwade, Russ. J. Coord. Chem. 35(12) (2009) 932-937.

[10] F. Gharib, K Zare, K Majlesi, J. Chem. Engg. Data. 45 (2000) 833-836.

[11] A. B. Naik, World J. Chem. 6(2) (2011) 118-121.

[12] A. A. El-Bindary, A. Z. El-Sonbati, M. A. Diab, S. M. Morgan. J. Mol. Liq. 201 (2015) 3642.

[13] A. B. Naik and M. L. Narwade, Am-Eur. J. Scientific Res. 3(2) (2008) 212-216.

[14] A. B. Naik and M. L. Narwade, Universal J. Chem. 1(1) (2013) 7-10.

[15] A. I. Vogel, A Text of quantative chemical analysis, Pearson, 2003.

[16] A. I. Vogel, A Text of quantative inorganic analysis, Longmann, London, 1978.

[17] L. Meities, Handbook of analytical Chem. McGraw Hill, New York, 1963, 187.

[18] J. Bjerrum, Metal ammine formation in aqueous solution, Cophenhagen, P Haase and Sons, 1941.

[19] M. Calvin, K. W. Wilson, J. Am. Chem. Soc. 67 (1945) 2003.

[20] P. Job's, Ana. Chem. 9(10) (1928) 113-116.

[21] A. E. Martell, M. Calvin, Chemistry of metal chelate compounds, Prentice Hall, Inc; Now York, 1956, 39-42.

[22] H. M. Irving, H. S. Rossotti, J. Chem. Soc. (1954) 2904-2910.

[23] H. M. Irving, H. S. Rossotti, J. Chem. Soc. (1953) 3397-3405. 